\title{
Bases da teoria atómica *
}

\begin{abstract}
"A ciência é uma aventura de toda a raça humana para aprender a viver e talvez a amar o universo onde se encontra. Ser uma parte dele é compreender, é conhecer-se a si próprio, é começar a sentir que existe dentro do homem uma capacidade muito superior à que ele pensava ter e uma quantidade infinita de possibilidades humanas.

Proponho que a ciência seja ensinada a qualquer nivel, do mais baixo ao mais alto, de um modo humanístico. Deve ser ensinada com uma compreensão histórica, com um entendimento filosófico, com um entendimento social e humano, no sentido da biografia, da natureza das pessoas que fizeram a sua construção dos triunfos, das tentativas e das tribulaçסes."
\end{abstract}

I. I. Rabi

Prémio Nobel da Física

\section{A - Introdução}

1 - Diversos autores têm-se debruçado sobre as características de que deve revestir o ensino das ciências físico-químicas ao nível das escolas secundárias. Verifica-se que nem sempre este ensino é satisfatório. As possíveis causas, algumas das quais apontarei adiante, são múltiplas.

2 - Por vezes, a ciência era apresentada ao nível do ensino secundário como uma construção abstracta do espírito, desligada da realidade experimental, cuja justificação era exclusivamente a sua coesão lógica intrínseca. Ora esta concepção é profundamente errada pois as formulaçð̃es teóricas devem estar estreitamente ligadas às respectivas fontes experimentais. Além disso este método pedagógico, que visava apenas preparar o aluno para dar respostas a certos tipos de perguntas mais ou menos estandardizadas, era árido e não era educativo, visto que não estimulava o desenvolvimento das capacidades de imaginação e o espírito crítico.

3 - Explorando de uma maneira sensata a interligação entre a experiência e a teoria, penso que o ensino de uma ciência poderá não ser só mais educativo, propiciando o desenvolvimento das capacidades do aluno, como também será menos árido e mais aliciante e atraente.

4 - De acordo com a filosofia do Projecto Nuffield a elaboração dos curricula científicos e até dos próprios conteúdos deve ter em conta dois factores importantes: a) Um grande número de alunos não continuará os seus estudos depois do $9 .^{\circ}$ ou $11 .^{\circ}$ anos de escolaridade, pelo que as matérias do curso devem ser seleccionadas de modo a constituirem um conjunto tanto quanto possível completo, harmonioso e formativo, susceptivel de fornecer uma cultura geral satisfatória.

b) Deve também atender-se aos interesses dos alunos que vão optar por química industrial, metalurgia, engenharia ou estudos académicos mais avançados, porque, para esta importante minoria, o curso deve também servir como uma adequada base para trabalho futuro, seja qual for a sua natureza.

5-O progresso tecnológico hoje em dia torna necessário elevar o nível do ensino da ciência.

6 - Os alunos devem adquirir uma compreensão, que dure para toda a vida, do que significa analisar um problema cientificamente e devem aperceber-se do que significa ser cientista, do que os cientistas estão a fazer e podem fazer. Isto tem pouco a ver com conservar na memória, por um tempo mais ou menos longo, a informação ditada ou lida, estática, sem vida. Por isso a ciência deve ser apresentada como um caminho que permite conduzir uma investigação sobre a natureza das coisas e como um corpo de informação construída pelas investigações de outras pessoas. $\mathrm{O}$ ensino deve ser orientado através de experiências planeadas para despertar o espírito de investigação. Devem ser proporcionadas oportunidades aos estudantes para observarem e explorarem por si próprios os fenómenos estudados de modo a desenvolverem um pensamento imaginativo e disciplinado e a tomarem consciência da parte importante que a ciência desempenha na vida moderna.

7 - Os estudantes devem aprender a distinguir entre os fenómenos observados e as explicaçð̋es apresentadas pelo pensamento criativo do homem e a aperceber-se que a interdependência entre estes dois aspectos complementares está na origem de todo o progresso científico. Os alunos deviam ter oportunidade de tomarem consciência desta inter-relação por experiência própria. Desde o princípio devem ser encorajados a pensar com imaginação acerca dos problemas que confrontam e a sugerir novas experiências e explicaçð̄es. É da maior importância que a sala de aula ofereça oportunidades para experimentação e observação.

8 - Julgo poder afirmar que os princípios pedagógicos propostos sucintamente nos parágrafos anteriores são geralmente aceites, não oferecendo contestação. Referi-os porque reconheço a sua relevância, mas não é deles que vou ocupar-me predominantemente neste trabalho. Defendo, sim, a necessidade de alargar o espectro das técnicas utilizadas na transmissão dos conhecimentos científicos. Entendo que este processo de transmissão dos conhecimentos se não esgota ao nível das faculdades intelectuais. Com efeito, a eficiência pedagógica exige o recurso a técnicas que, para além de não violentarem a razão, tirem partido de todos os aspectos capazes de despertarem a curiosidade e de atrairem a atenção. Tudo aquilo que causa aversão não é susceptível de ser conhecido e compreendido, isto é, aceite in-

* Trabalho apresentado durante o Estágio Pedagógico de 1983/84.

- Ladeira das Alpenduradas, 38, Coimbra. 
telectualmente. Para aprender os princípios de uma ciência é indispensável começar por gostar dessa ciência. É lamentável que a aventura do espírito humano que é a descoberta científica, por mais empolgante que seja, surja frequentemente apresentada de forma árida que completamente neutraliza a possibilidade de despertar o mais ténue simulacro de emoção. É essencial desenvolver materiais que auxiliem os professores a apresentar a ciência de uma forma viva, interessante e compreensível, como por exemplo folhetos educacionais, questionários, painéis, teatro, filmes, gravações, etc. Pretendo que o trabalho apresentado na secção $\mathbf{E}$ sob a forma de um folheto educacional possa contribuir para a resolução do problema equacionado.

\section{B - Objectivos do presente trabalho}

1 - Objectivos gerais

- investigar um problema de educação em Química

- escolher técnicas para a solução do problema de educação em Química

- aplicar as técnicas escolhidas

2 - Objectivos específicos

- apresentar os conceitos básicos relativos à Teoria Atómica

- identificar algumas das principais dificuldades dos alunos, na aprendizagem das bases da Teoria Atómica

- sensibilizar para a importância do método experimental

- propor métodos para facilitar a apreensão dos conceitos

- realçar a interdependência da actividade experimental e teórica de alguns dos primeiros químicos de modo a estimular o gosto pela ciência

\section{C - Método}

Os métodos pedagógicos clássicos não parecem adequados a propiciarem a apreensão de conceitos mais abstractos e estranhos à experiência do dia a dia por não explorarem plenamente as técnicas existentes para despertar o interesse e cativar a atenção. É desejável recorrer a métodos pedagógicos novos que permitam ao aluno viver, e em certa medida experimentar, a participação nos acontecimentos emocionantes que acompanham as descobertas científicas e o progresso resultante das contradiçJes entre as observaçōes experimentais e as consequências lógicas das formulaçōes teóricas aceites. O recurso ao relato de factos históricos é um expediente útil para o fim em vista. Assim, importa que não só sejam mencionados os nomes dos cientistas que contribuiram preponderantemente para o desenvolvimento de uma ciência como também que sejam apresentados episódios da vida desses cientistas relacionados com o avanço dos conhecimentos e que sejam referidas as etapas mais significativas do seu trabalho de investigação. Penso que a abordagem histórica de qualquer assunto científico é de grande interesse pedagógico por várias razões:

- Introduz o aluno no método científico. Este apercebe-se que todas as teorias não são simples afirmaçōes lógicas, mas que estão alicerçadas em inúmeras observaçōes e dados experimentais, sendo necessário um salto intelectual daqui para a teoria.

- Retira a aridez que por vezes cai sobre as diferentes teorias científicas e confere-lhes um carácter humano, isto é, com base em algo palpável ligado à vida dos seres humanos, com êxitos e fracassos.

- Introduz as leis pelo método indutivo (seguido pelos cientistas ao longo dos tempos) levando os alunos a ter um papel activo e não passivo.

Encontramos frequentemente jovens que sabem de cor os nomes de todos os jogadores das principais equipas de futebol. Este milagre da memória é facilmente explicado pelo facto de esses jovens viverem intensamente o desenrolar das lides desportivas. Quando formos capazes de lhes proporcionarmos também a sensação de estarem a participar, ou pelo menos a presenciar o desenrolar das lides científicas, conseguiremos certamente um assinalável progresso pedagógico. Pretendo que este trabalho seja um contributo para a resolução do problema exposto.

O recurso a um folheto educacional ou a uma dramatização teatral surge naturalmente, como auxiliar pedagógico apropriado ao objectivo pretendido. Embora a dramatização seja possivelmente mais motivadora, recorri ao folheto educacional porque neste os diálogos entre as personagens podem ser suplementados pelas respectivas biografias e por explicaçð̃es que ajudem a clarificar o texto.

Além disso, o folheto, destinado aos alunos do $8 .^{\circ}$ ao $11 .^{\circ}$ anos de escolaridade, tem as características de história ilustrada que pode ser lida em casa, com economia de tempo lectivo, e comentada depois na aula, onde serve de tema de reflexão.

Eventualmente este folheto poderá ser facilmente adaptado a uma dramatização teatral.

"Isto é de facto um mistério", (observou Watson) "O que pensa que isto quer dizer?" "Eu não tenho ainda dados. E um erro crasso teorizar enquanto se não têm dados. Sem dar por isso torcem-se os factos para os adaptar às teorias, em vez de adaptar as teorias aos factos."

"Sherlock Holmes", A. Connan Doyle

\section{D - Bases da Teoria Atómica}

1 - Proponho-me apresentar, numa perspectiva histórica e de forma adequada aos níveis etários do $8 .^{\circ}$ ao $11 .^{\circ}$ anos de escolaridade, a Teoria Atómica.

Este tema foi escolhido por constituir um dos principais fundamentos da Química Moderna e servir para ilustrar de forma exemplar a interligação do desenvolvimento teórico e do correspondente progresso experimental. A partir de factos concretos da História da Química vou procurar sensibilizar o aluno para o facto de em ciência, as formulações teóricas assentarem numa base experimental adequada e estarem na origem de novas experiências cujos resultados ou constituem confirmação, ou conduzem ao aperfeiçoamento ou até rejeição das teorias iniciais.

2 - Passo a resumir as bases da Teoria Atómica.

a) Muitos filósofos tinham-se debruçado sobre a natureza da matéria e os Gregos discutiram mesmo se a matéria seria infinitamente divisível, ou seria feita de um grande número de pequenas partículas que já não podiam ser divididas a partir de certa altura. A teoria que defende a existência de partículas esteve especialmente na moda entre os anos 430 e 280 a.C. Os seus adeptos chamaram-se atomistas sendo os mais famosos Leucipo, Demócrito e mais tarde Epicuro. Às partículas cuja existência foi postulada por estes filósofos chamamos átomos (átomo em grego significa indivisível). $O$ poeta romano Lucrécio, que viveu talvez entre os 
anos 98 e 55 a.C., admirador de Demócrito, no seu poema "De Rerum Natura", trabalho esse que não pode ser considerado primariamente como um texto de ciência, defende a existência de átomos invocando explicitamente a experiência do dia a dia, para mostrar que a Natureza recorre frequentemente a agentes invisíveis para efectuar as suas obras e que, portanto, os átomos podem existir apesar de invisíveis. Diz Lucrécio no seu poema:

"Se estenderes as tuas roupas na margem onde as ondas vêm bater, verás como ficam húmidas; se as pendurares ao sol, ficarão secas. Entretanto ninguém vê como é que a água entrou nelas nem como saiu delas, e isso só foi possível desde que a água se tivesse dividido em partículas que os nossos olhos não distinguem de maneira nenhuma. $O$ anel que trazemos no dedo vai-se, com o tempo, adelgaçando pelo lado de dentro... E que partículas são estas que se perdem constantemente?... É assim por intermédio de corpos invisíveis, que a Natureza realiza a sua obra."

É claro que, para Lucrécio, a água que se evapora e os objectos que se gastam com o uso constituem evidência da estrutura corpuscular da matéria.

b) Robert Boyle (1627-1691) considera que a sua Lei da Variação do Volume dos Gases com a Pressão, verificada experimentalmente, constitui prova da existência de átomos separados por intervalos que se tornam maiores ou menores consoante os valores da pressão. c) Robert Boyle, entre outros, contribui experimentalmente para a noção de substância elementar (para ele "elemento") e de composto. Para este cientista uma substância é um "elemento" se não pode ser decomposta quimicamente.

d) John Dalton (1760-1844) constata experimentalmente que nos compostos diferentes, formados pelos mesmos elementos, há uma relação numérica simples entre as massas diferentes dum desses elementos que se combinam com uma mesma massa do outro elemento. Por exemplo, Dalton verificou que no metano e no etileno a proporção de hidrogénio para carbono é, no primeiro composto, dupla da do segundo, o que sugere claramente a existência de unidades elementares constituintes da matéria.

3 - A formulação teórica construída por Dalton para interpretar os resultados dos seus trabalhos experimentais é a seguinte:

a) A matéria é constituída por átomos indivisiveis.

b) Os átomos são imutáveis.

c) Os compostos são constituídos por moléculas ("átomos compostos"').

d) Os átomos ou as moléculas em cada substância pura são idênticos.

e) Os átomos de elementos diferentes possuem massas diferentes e os do mesmo elemento a mesma massa.

f) Nas reacçð̋es químicas os átomos apenas se rearrajam, não se criam nem se destroem.

4 - A importância da teoria de Dalton é evidenciada pela abundância de consequências científicas de relevo, tais como:

a) Capacidade de sistematizar factos e leis conhecidas - por exemplo: harmonizar a Lei das Proporçōes Definidas de Proust com a Lei da Conservação da Massa de Lavoisier.

b) Esquema conceptual manejável - a própria Lei das Proporçðes Múltiplas que sugere a introdução de fórmulas químicas.

c) Capacidade de sugerir novas relaçð̃es e estimular novas investigaçð̃es - determinação de massas atómicas.
5 - A Teoria de Dalton confrontada com novos resultados experimentais.

Gay-Lussac (1778-1850) efectuou uma série de experiências de grande interesse, verificando, por exemplo, que um volume de oxigénio se combina com dois volumes de hidrogénio para formar dois volumes de vapor de água; um volume de azoto reage com um volume de oxigénio para formar dois volumes de óxido de azoto, etc. Após ter efectuado outras medidas experimentais análogas, Gay-Lussac encontrou que, na reacção entre gases à mesma temperatura e pressão, os volumes dos gases estavam sempre numa relação de números inteiros - isto é, um, dois ou três, etc. volumes de gases mas nunca fracçð̃es.

Da mesma maneira que a teoria cientifica nos ajuda a descobrir regularidades insuspeitas dos fenómenos naturais, os preconceitos podem ter o efeito oposto ocultam a realidade. Assim Dalton recusou-se a atribuir significado aos resultados de Gay-Lussac relativos à combinação de oxigénio e hidrogénio, por não se enquadrarem no seu esquema teórico sendo induzido em erro, apesar da sua intuição genial. É que se se admitir que volumes iguais de gases (à mesma pressão e temperatura) contêm o mesmo número de partículas, os resultados de Gay-Lussac significam que átomos de hidrogénio se combinam com átomos de oxigénio (sendo o número dos primeiros duplo do dos segundos) para formarem tantas moléculas de água quantos os átomos de hidrogénio disponíveis, mas, então, os átomos de oxigénio teriam de se dividir, o que era contrário à hipótese de indivisibilidade dos átomos.

6 - A ciência progride quando se conciliam resultados experimentais aparentemente contraditórios no contexto da teoria ou teorias existentes.

Avogadro (1776-1856) sugeriu que as substâncias elementares não são em geral formadas por átomos livres mas por agregados de pequenos números de átomos chamados moléculas e defendeu que volumes iguais de gases, à mesma pressão e temperatura, contêm números iguais de moléculas (e não de átomos como se pensava previamente). Conseguiu assim harmonizar a Lei das Proporçð̃es Múltiplas de Dalton com a Lei da Combinação de Volumes de Gay-Lussac, abrindo deste modo caminho para avanços da máxima importância tais como a determinação rigorosa de massas atómicas e o estabelecimento definitivo de fórmulas químicas.

\section{E - Folheto Educacional}
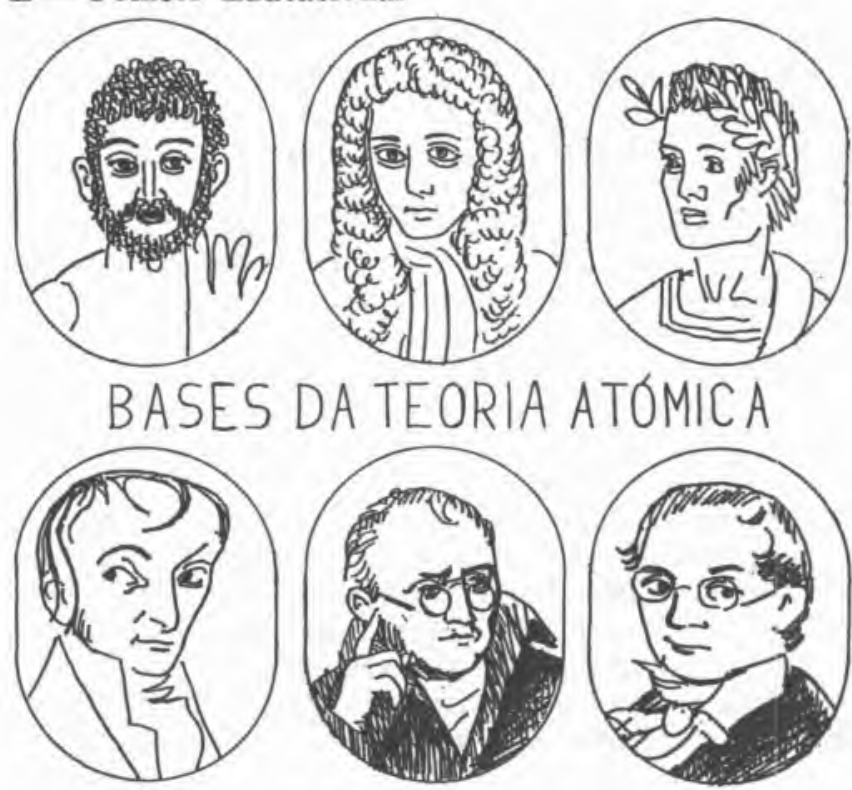
Haje todos salemos que a materia á constituida par ćtomos.

Qual a histibria misteriosa face. manta que a palauna átormo encerra? Quem se tará lambrado, e porgue., de dizer que a maléria a' contiturida por áliomos?

Esta pallaura preverm do vocábulo gre go "atomos" que significa indivisivel. Por volla do amo 500 a.c. os filósofos gragos discutiarm, se seria possivel di vidir a maliria indefinidamenta. ou, se este processo taria nacessaria. menti um fim quando se chegas se a una particula iltiona que não pudesse ser dividida. Esta dis. cussão prelongousse durante séculos davido a mäo ser possivel apresentar argumentos conclustios a faver on contia a hipulierse atiomítica por suta se referir a partículas sitramamentes pe. quemas en imacussivieis ars sentidos.

\section{LUCRECIO}

Poeta e filósofo romano. Viveu de 98 a 55 a.C..

Escrevel o poema "De rerum natura" no qual retorna as ideias de Democrito relativas à estrutura atomistica da mateiria.

Ensimaste, ó Damoerito, que a materia 2' fromada por átämos. Como estas să vin visideis, os unsemsatios măo acreditam ma sua existincia. Esquecam-se, mo entanto, que a Natiuranga necorre jrequentionente a agentas invlisideis para pactuar as suas dras. Sa standeres as tias noupas ma margem onde as ondas viom bater, veris como fieam himiclas. Se as perndurares as sol, ficanăo sacas. Ninguim vê como é que a dgua entrou nulas mam como a' que saiu dalas. Porém, isso só joi possivel porque a água se dividue am partículas que os mossos dhos măo enxergam. Estou, portanto plana mente de acoido contigol

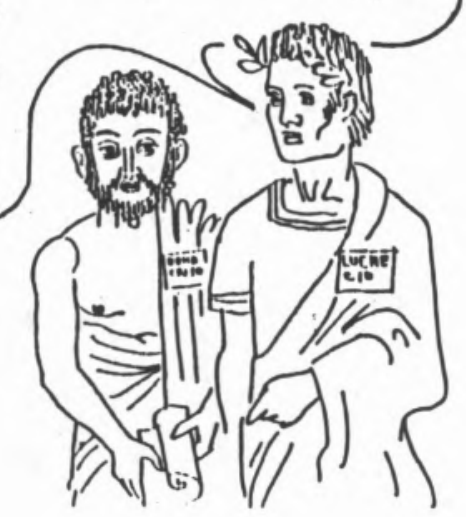

\section{DEMOCRITO}

Filósofo grego, discipulo de Leucipo. Viven de 460 a 370 a.C.

Defendeu que a maténa é constituida por particulas indivisiveis.

A matria mão pode ser dividida inde. jomidamente pois é constitivida por paquanas particulas anvisivais e indivisiveis, os átomes, que, sem conta, se agitam mo esface varjo 2 se combinam para formarem o universa as plantas, os animais a os seres burmanos. Arsiom, for viemplo, quando suma árvore masce, ertas átomos, em mimeros cada vay maiores, văo - se combinando antre sic para formarem assa buvore. E quando a árvore morre a se decompä́, os d́tomos măo să dastruidos, mas comblimam - re movamente para for. marem outhas coi. sas.

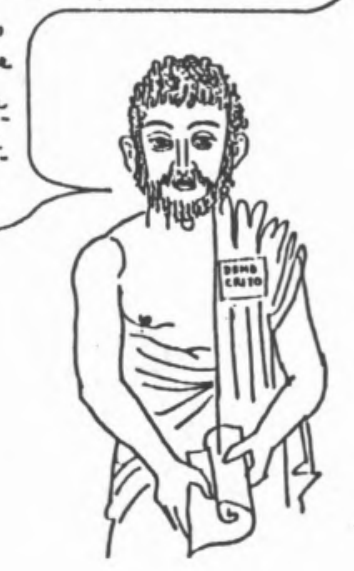

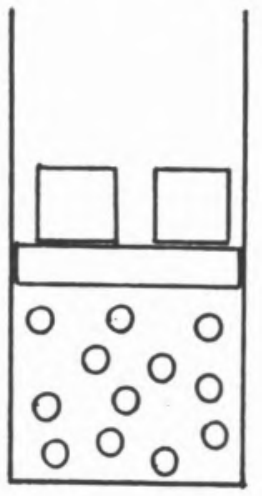

Esquema de interpretaçao atomística da variaçăo do volume de um gás com a pressão 


\section{ROBERT BOYLE}

Químico e físico irlandês Viveu de 1627 a 1691.

Estudou a compressão e a expansão do ar $c$ de outras gases.

Observou que o volume de um gás a temperatura constante varia inversamente com a pressão.

Insistiu na importáncia de fundamentar experimentalmente as teorias cientificas

Maus amigos, os voress argumentos mă converm. um ! Năo nă insernsalos os que os rejeitionn! Provas seginas siso só aquelas que ne baraiam em factos indiscultiva is da experiência.

Notaram já que qualquer gás pock ser forcado a scufar rum volume manor, aue mentands entrios a sua puessäs ma rangio am

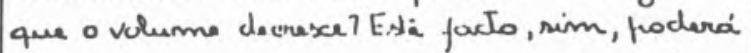
ser urma prova clara da existáncia da átomos reparados for intévalos, os quais, setornam maiores ou onamous consoanti. os valores da prassă.

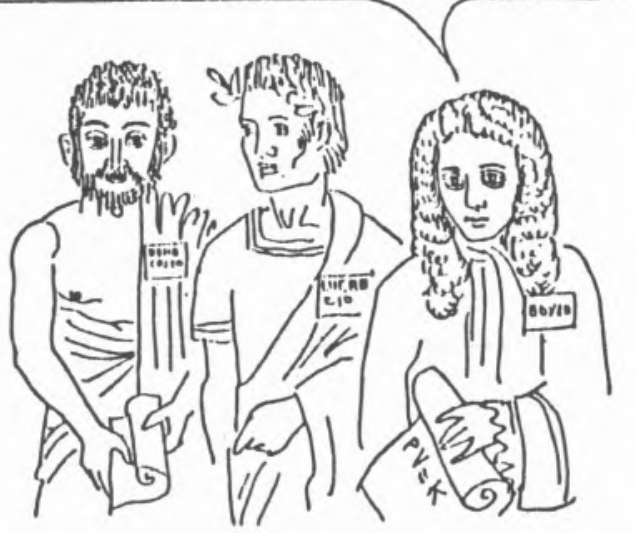

\section{JOHN DALTON}

Mestre escola e quimico inglês. Viveu de 1760 a 1844 .

Propós em 1803 a Teoria Atómica a qual constitui o fundamento da quimica moderna.

Deduzill da sua teoria a Lei das Rroporções Múltiplas e fórmulas quimicas mostrando a com. posição das moléculas.

Apresentou a primeira tabela de massas atómicas.
Aproveito para vos ticanmmitir algo mals. Quais sü os "slamentos" da Natureara? sertos o fogo, o ar, a degua a a tarra como algums remsam I E' muito simples a res polia. "Ellementos" mä́ sö essas substân cias, mastodas arpuelas que por proces. sos físlcos e químicos se mã decompãm moutias.

Quando os "Alarnantos" se combinam entie si formam compostos.

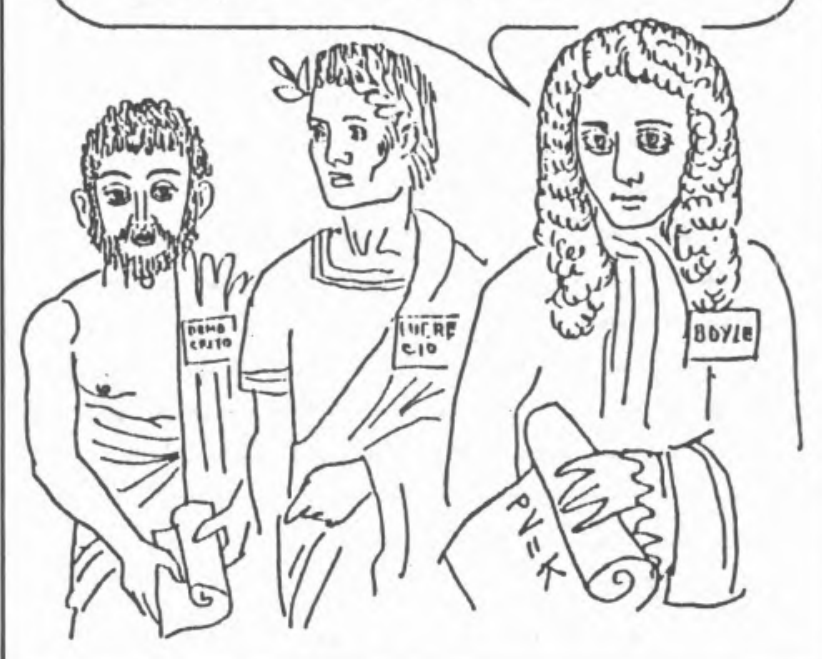

Meus ilustres predecessores: Dusejo revel ar-vos uma impertamia dexcotertia qie fis, estirdando diversos compostos foumados pulos mesomos elementos. Var. rifiquai precisamentie que estas se combi. mam sugundo proprorçás milliplas simplas, isto e, varifiquai que existem rolaçăs mu máricas jequamas emtire os dijerantas mamas da um clessas elannantios que se combinam com a mesma masser do outiro elemento. Esta. propriedada contitiei a prata mais clara qua connace da axislancia dos átiomos. Como, de outro modo, re joderia compreandar que a proporcäos de Ridroginio para corlano forse, mo matamo, precirsamente o ddero da corrasi, ondante proporsăo

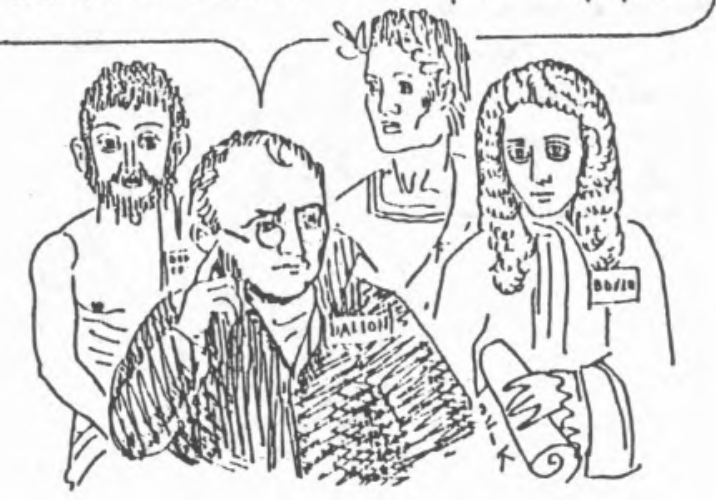




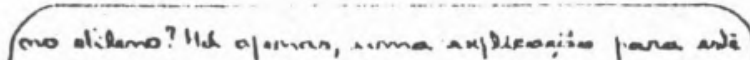
facto. 0 "átormo compurto" ( que mais tanda me deme mimará ondicula) de onetamo í constituido por dais átormos de hidrogimio a um átiono de carborno, enquanto que o"ditomo composto" da stilemo é constitrido por uon átarmo de tidrogénio - eurm dtarmo de carbono.

Rasoumedarmanti posso afirman-vos o reguinta:

1-A matiria e contituida por átomos vidivisiveis.

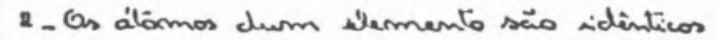
e possecern a merama massa.

3 - Cos diomos de stamentos didintos posaem marras difarentas.

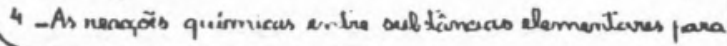

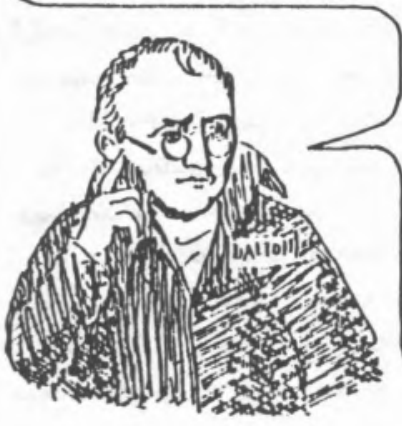
formarem compostos po dammer explicadas fabia combimaçäo de attomos.

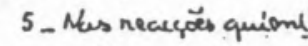
cas, os ćlomos onă be criarm merm se destridm a enas se agrup a am de mameiras dijeremtes.

○ $\dot{\oplus} \dot{0} \hat{0} \dot{\theta} \dot{\oplus} \dot{0} \dot{0}$

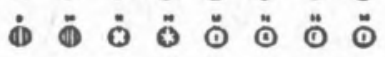

$\ddot{\odot}$ ఠ $\ddot{0} 0$

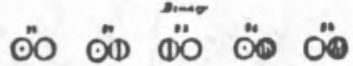

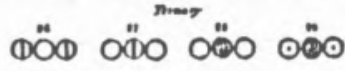

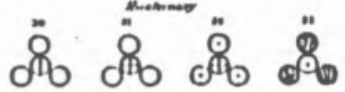

of 888

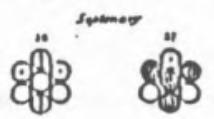

Simbolos de Dalton para os "átomos sim. ples" " "átomos compostos", extraidos da sua obra, "A New System of Chemical Philosophy", Part I.

Escreveu Dalton, Esta gravura contem os simbolos arbitrários on sinais escolhidos para representar os diversos "elementos químicos" ou partículas últimas"

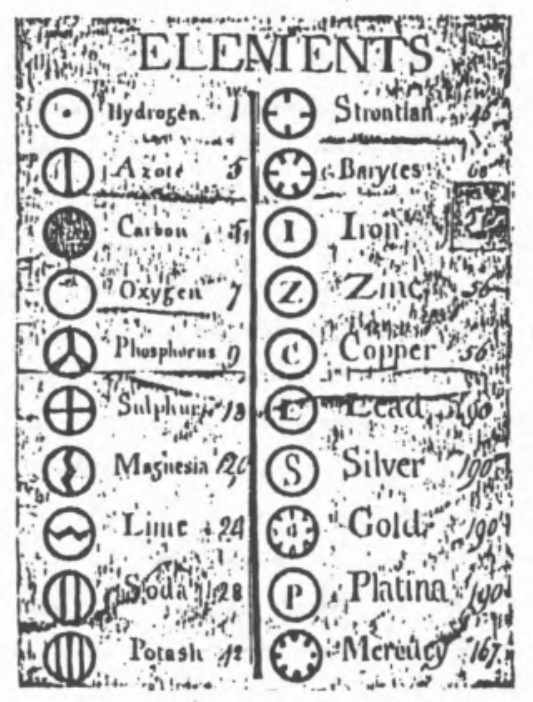

Lista dos "elementos químicos" segundo Dalton. Alguns destes não são efectivamente elementos.

Os números indicados a seguir aos nomes dos "elementos" representarn o cálculo das respectivas massas atómicas em relação ao hidrogénio.

Posteriormente a simbologia de Dalton foi substituida pelo sistema de letras proposto por BERZELIUS em 1814. Por exemplo, oxigénio - $\mathrm{O}$, hidrogénio - $H$.

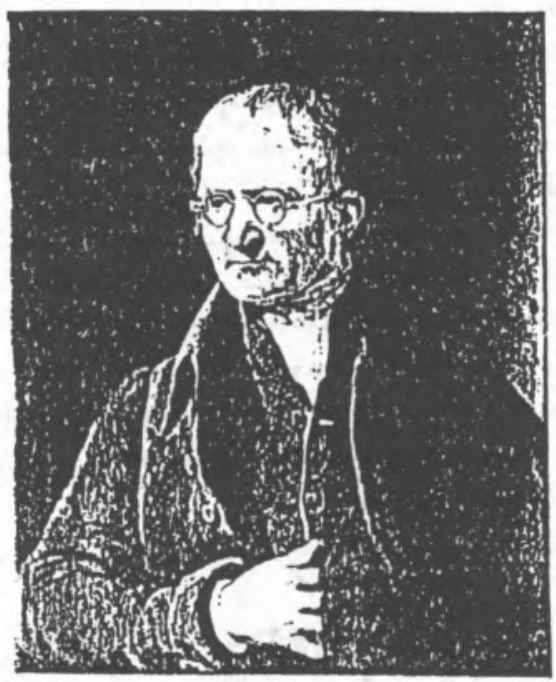

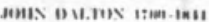

As contriburções Jundamentais de Dalton para a Química foram a idera que os átomos de elementos diferentes têmmassas distintas e a concepção de que as reacc,bes químicas ocorrem através da combinação dos átomos. 
Desejo comumicar-Nos os ressultados uniorissi mos de algumas olsenvagärs que tanho vindo a faser. Efectivamente, constatal que mas reaceats eintrea gases à masma temperatura a pressäo, os volumes dos gases astäs sempre muma rulaçăo de numeros inturos simples. Com efeito, varifiquai, cuistadosamente, que um volume de oxigínio se combina com dois volumes de hidrogimio para formarem dois volumas de água, a que eum volume da aygto se contiona corn um volume de oxigimio para formarem dois volumes de óxido de angto. Tharizyi ainda, atim dastas, muitas outras experieincias que confirman a lai que anumairi.

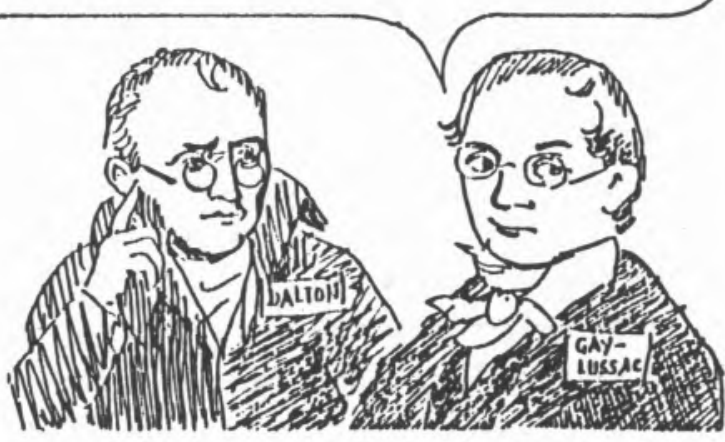

uay-Lussac, seria macessdirio que.cada um dos átormos de oxiginio se dividisse a maio e que meio álömo de oxigínio se combinasse com um átomo de hidrogínio para formaram um "dtomo composto" de água. Porim, os átomos de oxiginio mă podem dividir-se. Visto que os átomos săo indivisiveis, mă há altermativa : o"átomo compoto" de água reselta da combrimaçäs de um átōmo da aigámio com um átormo de hidrogimio.

As suas afiumaçōes, Sentron cagay-Luessac, săo rortanto falsas.

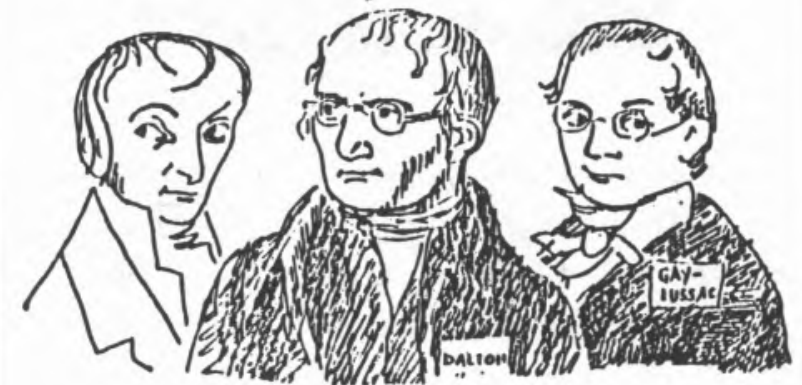

\section{JOSEPH-LOUIS GAY-LUSSAC}

Quimico e físico francês. Viveu de $1778^{\circ}$ a 1850 .

Descobriu a lei que descreve a variação do volume dos gases com a temperatura.

Observou que no estado gasoso as substâncias elemertares se combinam entre si para formarem compostos segundo relações volumétricas simples.

Senther yay-Lumac, paracem-ma muito estrambos os seus nesultados axperimantais. Parmito-me questioná. los com lase mem argumento alannentar. Como tive oportimida che de rejerir, verifiquai que os elementos se combinam segundo proporçörs miltiplas simples, quanto ds massas. Por outro lado há quem adrnita que volemens iguais da gases contan nimaros iguais de parti. culas. Mas para gere um volume de oxi gimio se combinasse, com dois volumes de hidrogímio fara formarem dois volumer de vapior de degra, como ajirma o Sembor

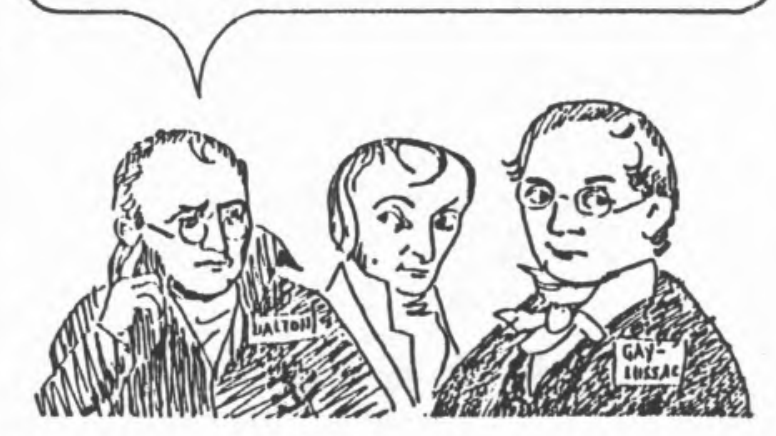

\section{AMEDEO AVOGADRO}

Químico efísico italiano. Viveu de 1776 a 1856.

Sugeriu que as substâncias elementares não existem necessariamente na forma de átomos simples mas como combinações de pequenos números de atomos denominadas moléculas e que em geral os gases são constituidos por moléculas formadas por mais dum átomo.

Afirmou que volumes iguais de gases nas mesmas condicōes de pressão e temperatura contém igual número de moléculas. As suas ideias permitiram corrigir as formulas quí. micas propastas por Dalton. 
Pregado Semhor Dallion, tembo o maior apreces pelo seu brithante continbuts para o avame do

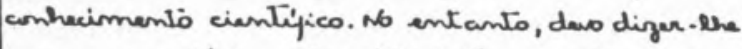
que as suas ideias mäs eltï̈ in firamente correctas. Alidis, o Santer möotem o direito de ignorar fados que se aprasentarn com uma sólida base experimental, só porques esten se mäo adaptam a neue esquema tiónico, como i' o caso das experien cias do Sentior cajay-luessac. O que é preciso í never a sua ticria a alaptd-la aos factos da experiencia.

Na vandade, volurmes iguais de gases, mas masmas condiçöes da juesssä a Campuratura, con tam nimeros igrais de mdécullas, or "átormos compotos" segundo a sue desirynac.ăo.

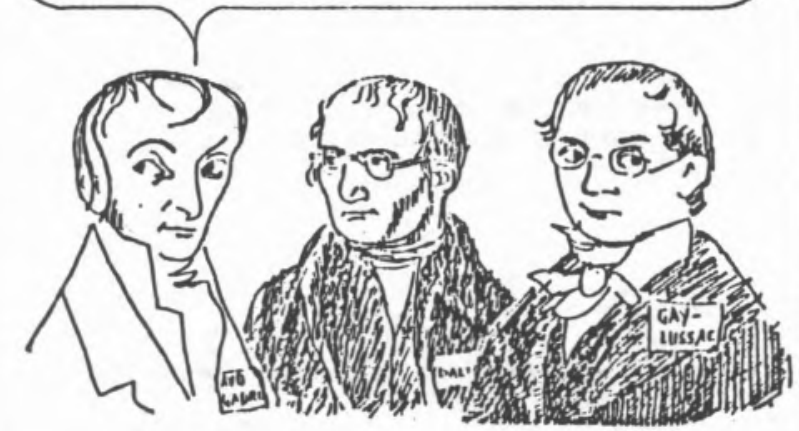

Podomos sintetizar do seguince modo o diálogo en tre Dalton, Gay-Lussac e Avogadro:

Dalton constatas que o oxigénio o o hidrogónio se com. binam para produeir vapor de água e interprotou este jocto admitindo que os "átomos compostos" do vapor de água resultam da combinação de um ábomo de onigo:nio com um átomo de hidrogénio

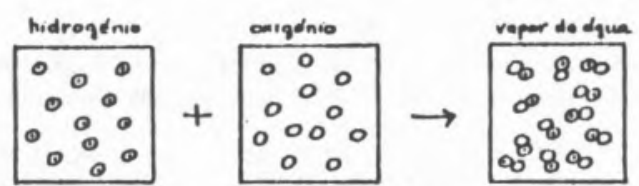

Esquema teórico imaginado por Dalton mas hoje abandonedo

As dvervaçöet de Gay-lussac podem esquematizar10 do sequinte mode !

\begin{tabular}{|c|c|c|c|c|}
\hline $\begin{array}{l}2 \text { velumeses } \\
\text { hidrogegense }\end{array}$ & + & 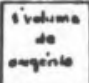 & $\rightarrow$ & 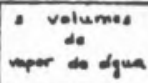 \\
\hline
\end{tabular}

É flogrante a incompatiblidade entre este esquama e a concercäo de Dalton, a qual condusiria ab esque. me. segunte:
Tal a' o caso do oxigimlo a do hidrogimio, unfas moldculas scio formadas por dois átomos podando, portanto, dividir-se an cluas partis iguais. Ao con? Fidrlo do que o sentior ajurma, a ondícula de água é constiturida por dois átiomos de hidrogímio e um de oxigínio, pols nesulta da combinaşăs de una molicula de hidroginio com meia molicula da oxigínia

É assiom que a sua lei das properçăs mils. Aplas a lai da combimaşăo dos vetumas do Saminor cyay-Lussac, mă só mäu estä am contradiçoo, mas ata' se tharmanizam per feitamenta a se completarm, permitiondo à detarminaçăo nigorosa de massas ututimicas e - estabelaciomento de fórmular químicas.

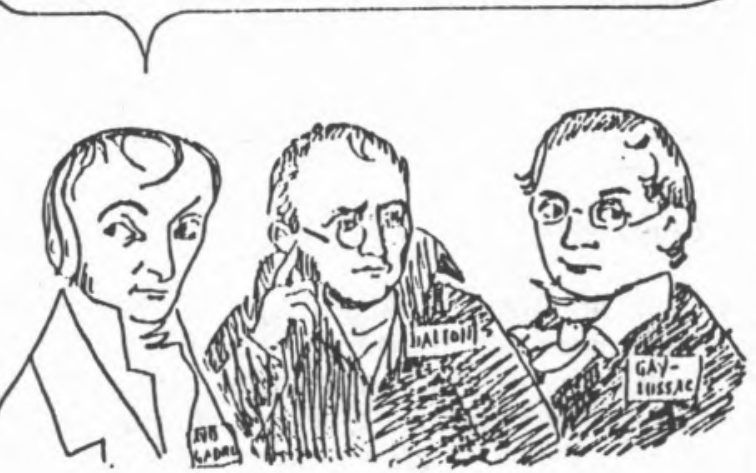

Em um volume de axigéno não há átomos em nú. mero suficiente para se combinarem com os átormos de dors viumes de hairogénio

Avogadro resolve o dilema propondo o seguinte esquema.

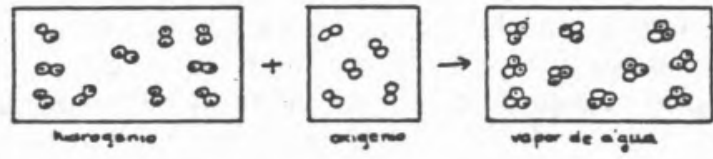

Pare Avogadro volumes iquais de gases contêm núme. ros iguas de mole'culas, hupótese de Arogadro, eño de átomos, como se pervava, pas segundo este cientista, as subs tâncias elementares näo säo sempre farmada por ótormos livres. mas por moleiculas constituidas por pequenes mimeros de átornes. Por exempio, ada maiécula de arigénio écorstitui. da por das ábornos, sucedenda o mesmo com cada mole'cula de hidrogénio: Assim se explica a formacäo de moléculas de água, cada uma constituida por um átomo de oxigénio e dois átomos de hidrogénio. 


\section{CONCLUSÃO}

A hipcteve de Avojadro estabelace a dustim. con antra ditormos a onctliculas, quer ne tiate de selistancias elementares quer de substancias compostias. Esta hiputase permi tin resclver o dilema que se stabelaceu apoi as descibertias experimentiais de Dalton e vay-Lursar tiencto am conta - prasseppoto de que o átomo é uma particula inditusivel. Dapais de Avogadno jí muito mass se aprendeu acerca do átomo... mas isso e' outira historia. Talaz as Viabulkos destes piomeiros chos paraçarn agora neanctos a simples, contudo alas săo o functamento da descebertas que continuarm ainda nos morsos dias.

\section{F - Conclusões}

Propus-me apresentar, numa perspectiva histórica e de forma adequada aos níveis etários do $8 .^{\circ}$ ao $11 .^{\circ}$ anos de escolaridade, os conceitos básicos relativos à Teoria Atómica e a interligação do desenvolvimento teórico e do correspondente progresso experimental e, a partir de episódios concretos da História da Química, motivar o aluno e sensibilizá-lo para o significado do método científico, dando realce à actividade de alguns pioneiros.

$\mathrm{Na}$ minha opinião estes objectivos foram plenamente atingidós com à elaboração do folheto educacional referido na secção E. Com efeito, este trabalho contem informação útil, apresentada num estilo simples e coloquial, acessível aos alunos do $8 .^{\circ}$ ao $11 .^{\circ}$ anos de escolaridade, sendo o texto ilustrado de forma atraente. Talvez pareça demasiado elementar para o $100^{\circ} \mathrm{e} 11 .^{\circ}$ anos mas neste caso poderá servir de base para trabalho mais aprofundado dos alunos, como tema de debate sobre a evolução dos conceitos científicos, etc. $\mathrm{O}$ tema é desenvolvido de maneira encadeada e evolutiva, susceptível de prender a atenção, despertar o interesse, sendo mantida uma certa atmosfera de expectativa em relação ao desenrolar dos acontecimentos, por forma a dar ao aluno a impressão de tomar parte neles. Relata o próprio avanço da ciência oferecendo uma panorâmica geral da evolução das ideias, com referência progressiva aos dados colhidos da experiência.

Não referi os contributos importantes de muitos pioneiros da Química, porque um folheto deste género se tornaria fastidioso, se fosse alongado excessivamente, acabando por obscurecer os aspectos mais relevantes da evolução da Teoria Atómica e correndo o risco de perder virtualidades pedagógicas. Eventualmente, o trabalho poderá vir a ser melhorado através do alargamento do seu âmbito e da adaptação a diferentes idades. No entanto, tal alargamento deverá sempre ser condicionado pelas características de simplicidade e acessibilidade e controlado por experiências pedagógicas.

Gostaria de ter podido experimentá-lo e de estudar as reacções dos alunos. Teria sido uma oportunidade de verificar em que medida os objectivos eram atingidos e quais as correcçð̃es que deveriam ser introduzidas quer no modo de apresentar quer no aprofundamento que dei ao tema. Possivelmente poderia ser aconselhável esclarecer outros pontos para melhor compreensão dos diálogos. É minha intenção ensaiar este folheto nos próximos anos, já que não me foi possível fazê-lo no decurso do presente ano lectivo. Estou convencida de que o ensino das matérias nele consideradas será muito facilitado pelo seu uso.

Agradecimentos:

Desejo deixar expresso o meu afectuoso agradecimento ao João pelas ilustraçðes do folheto educacional e à Constança por ter dactilografado o trabalho.

\section{G - Bibliografia}

1 CANE, B. e SELlWOOD, J., Certificate Chemistry 3, Schofield \& Sims Ltd, Huddersfield, 1973.

2 CARVAlHO, R., História do Átomo, Atlântida Editora, Coimbra, 1975.

3 CORREIA, C., NUNES, A., Química $-100^{\circ}$ ano de escolaridade, Porto Editora, Porto, 1983.

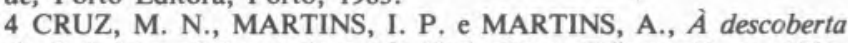
da Química - 8. ${ }^{\circ}$ ano de escolaridade, Porto Editora, Porto, 1983. 5 DAVIES, L., DENIAL, M. J., LOCKE, A. W. e REAY, M. E., Investigating Chemistry, Heinemann Educational Books, London, 1978.

6 FABER, E. (Editor), Great Chemists, Interscience Publishers, New York, 1961.

7 FARIA, A. M., VALADARES, J. A., SILVA, L. G. e TEODORO, V. D., $F Q 8-2 .^{\circ}$ volume Química, Didáctica Editora, Lisboa, 1982.

8 FORMOSINHO, S. J., GIL, V. M. S., DIAS, J. T. e CARDOSO, A. C., Química para ti $-8 .^{\circ}$ ano, Departamento de Química, Universidade de Coimbra, Coimbra, 1984.

9 GONÇALVES, M. C. M., PEREIRA, M. H. J., Química - $10{ }^{\circ}$ ano, Ediçðes Nave, Lisboa, 1982.

10 HOLTON, G., Introduction to Concepts and Theories in Physical Science, Addison-Wesley Publishing Company, Reading, Massachussets, 1973.

11 NUFFIELD CHEMISTRY, Introduction and Guide, Longmans/ /Penguin Books, London, 1966.

12 PURI, O. P., Concepts in Physical Science, Addison-Wesley Publishing Company, Readings, Massachussets, 1970.

13 ROGERS, M. J. W., Dalton and the Atomic Theory, Nuffield Foundation, Longmans/Penguin Books, London, 1966.

14 RUTHERFORD, F. J., HOLTON, G. e WATSON, F. G., Projecto Física, Fundação Calouste Gulbenkian, Lisboa, 1978.

15 SHONLAND, Sir B., The Atomists 1805/1933, Oxford University Press, 1968.

16 SOUSA, M. H. C., O Mundo dos Átomos - Química $100^{\circ}$ ano, Livraria Almedina Editora, Coimbra, 1982. 